\title{
EDITORIAL
}

\section{INTEGRASI PENDIDIKAN, PENELITIAN, \& PELAYANAN YANG BERKUALITAS DALAM ACADEMIC HEALTH SYSTEM}

\author{
Rizaldy Taslim Pinzon, Maria Silvia Merry \\ Fakultas Kedokteran Universitas Kristen Duta Wacana Yogyakarta \\ Email: drpinzon17@gmail.com
}

Pelayanan kesehatan di era ini mengalami perubahan sesuai dengan pengaruh situasi global, kemajuan pesat di bidang informasi dan teknologi, serta tingginya mobilitas penduduk dunia. Hal tersebut menyebabkan pelayanan kesehatan juga terdampak dengan menghadapi berbagai tantangan, yaitu: 1) pola penyakit yang berubah, 2) perubahan proporsi populasi dan demografi, 3) disparitas pelayanan kesehatan dan tuntutan masyarakat. Perubahan sistem pelayanan kesehatan di Indonesia sejak tahun 2014 dengan diberlakukannya Jaminan Kesehatan Nasional (JKN) juga turut berandil besar dalam perubahan pola pemberian pelayanan kesehatan yang cukup bermakna.

Situasi global dan nasional tersebut membuat para penyedia layanan kesehatan tidak dapat lagi menggunakan pendekatan lama dalam memenuhi kebutuhan masyarakat. Dokter di era saat ini harus mampu beradaptasi dengan perubahan teknologi kesehatan yang cepat, digitalisasi pelayanan kesehatan dalam bentuk rekam medik elektronik, mampu berkolaborasi dan bekerja dalam satu tim baik local maupun regional, dan tetap menunjukkan rasa belas kasih (compassion) dalam melayani pasien sehari-hari. Dokter juga dituntut untuk merubah paradigma pelayanan dari fee for services menjadi prospective payment system di era JKN. Dokter harus terbiasa pula dengan perubahan pola rujukan dan rujuk balik di era JKN. Perubahan paradigma pelayanan kesehatan akan memberi ruang yang luas bagi RS rujukan untuk benar-benar fokus pada pelayanan kasus spesialistik dan mengembangkan pusat-pusat pelayanan unggulan dalam bentuk center of excellence dan one stop services. Unit unggulan tersebut tidak hanya mumpuni dalam bidang pelayanan, namun juga unggul dalam bidang penelitian dan inovasi tatalaksana penyakit.

Perubahan situasi yang signifikan tersebut seharusnya ditangkap oleh institusi pendidikan kedokteran sebagai arus utama yang mewarnai kurikulum dan aktivitas akademiknya. Fakultas Kedokteran (FK) saat ini tidak hanya diharapkan untuk menghasilkan lulusan dengan nilai akademik dan keterampilan klinis tinggi namun juga harus siap dan mampu beradaptasi dengan perubahan paradigma dan tantangan dalam pelayanan kesehatan baik lokal maupun global. Tujuan penulisan makalah ini adalah mengenalkan konsep Academic Health System dan penerapannya sebagai salah satu pendekatan untuk menyiapkan lulusan FK yang siap melayani dalam situasi global saat ini.

Tujuan terbesar dari suatu institusi pendidikan kedokteran adalah menyiapkan lulusan yang siap pakai dan mampu bekerja serta bersinergi dalam sistem pelayanan yang ada. Dalam hal ini, dokter diharapkan mempunyai kompetensi klinis dan keterampilan komunikasi yang baik, matang secara pribadi dan professional serta ketajaman dalam analisis dan pengambilan keputusan. Pengetahuan dan pengalaman terkait sistem dan administrasi juga penting untuk memperlancar pelayanan. Untuk itu, proses pendidikan tidak cukup dibekali dari dalam fakultas dan rumah sakit pendidikan saja, namun juga harus 
berkolaborasi harmonis dengan sistem pelayanan kesehatan secara luas. Dokter yang dihasilkan oleh FK diharapkan mampu menjadi garda depan/ gatekeeper di pelayanan primer, memahami sistem rujukan, rujuk balik, dan terbiasa dengan konsep managed care. Dokter juga harus mampu bekerja dalam satu tim dengan profesi lain untuk memberikan pelayanan yang berfokus pada pasien (patient centered care).

Integrasi dan harmonisasi pendidikan kedokteran dan pelayanan kesehatan dalam satu sistem dikenal dengan nama Academic Health System (AHS). Dalam AHS, RS pendidikan dan jejaring lain (sebagai pusat pelayanan) dan FK (sebagai pusat pendidikan) akan bekerjasama dalam memberikan pelayanan kesehatan, mengembangkan inovasi-inovasi unggulan, dan penelitian yang pada akhirnya berujung pada peningkatan derajat kesehatan masyarakat. Sistem ini menjadikan pelayanan kesehatan dan pendidikan dokter terintegrasi. Sistem ini akan memperkuat RS dengan unit-unit unggulan spesialistik yang bukan hanya maju dalam hal pelayanan, namun juga penelitian dan inovasi. Fakultas kedokteran yang terintegrasi dalam sistem pelayanan kesehatan dengan satu atau lebih RS dan pusat pelayanan kesehatan primer akan memberikan kontribusi peningkatan kapasitas para dokter dipelayanan kesehatan sebagai dosen pembimbing klinik utuk terlibat dalam hal penelitian dan publikasi. Bukti empirik menunjukkan bahwa RS yang terlibat dalam AHS akan mampu menjadi pusatpusat unggulan untuk pelayanan yang berbasis organ (misalnya: brain center, heart center) atau berbasis penyakit (misalnya: stroke center, diabetes center). ${ }^{1}$ Dampak positif dari meningkatnya penelitian tersebut adalah meningkatnya publikasi ilmiah seiring dengan dilibatkannya para dosen pembimbing klinik.

Kolaborasi kerjasama yang baik dari FK dan RS serta fasilitas kesehatan primer nantinyaakan menghasilkan lulusan dokter yang siap pakai di lapangan kerja kesehatan. Lulusan dokter akan memiliki ciri $5 \mathrm{C}$, yaitu: 1) Care anywhere (mampu menggunakan teknologi kesehatan untuk memperluas pelayanan), 2) Care in team (memiliki kemampuan untuk bekerja dalam sebuah tim interprofesional), 3) Care in large data sets (mampu melakukan pengkajian perbaikan dalam pelayanan kesehatan dan penelitian dengan data yang besar/ registry), 4) Care by machines (pelayanan medis menjadi sangat digital dengan presisi yang tinggi), dan 5) Compassion (dokter mampu memberikan pelayanan kesehatan dengan empati yang tinggi dan rasa welas asih).

Selain meningkatkan kuantitas dan kualitas penelitian dan publikasi, integrasi dalam pendidikan dan pelayanan kesehatan dalam Academic Health System akan memberikan bekal pemahaman yang baik pada dokter lulusan FK akan sistem pelayanan kesehatan rujukan dan rujuk balik di era JKN (Gambar 1). Sistem piramida pelayanan kesehatan akan mengharuskan dokter lulusan berada di garda-garda terdepan pelayanan kesehatan primer. Pendidikan kedokteran harus lebih banyak berfokus pada penyakit-penyakit yang harus dikuasai dengan kompetensi yang memadai. 


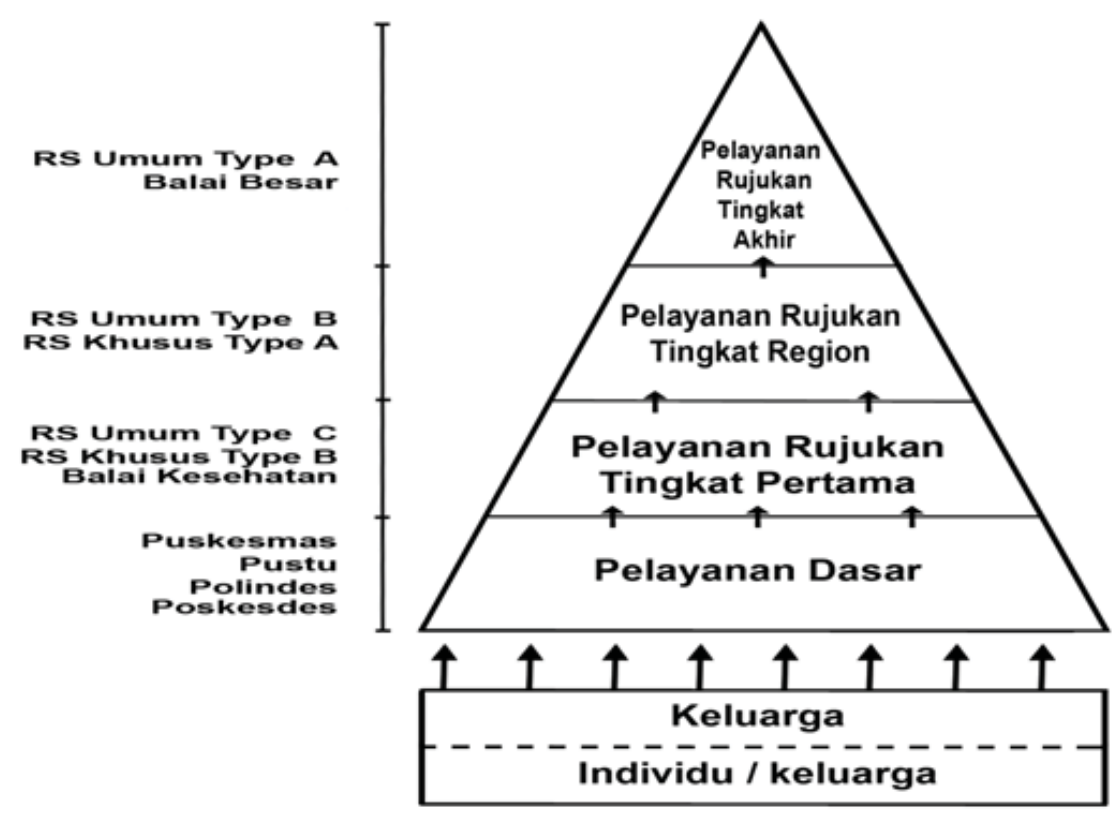

Gambar 1. Sistem pelayanan kesehatan di era JKN

Sistem terintegrasi ini akan memperkuat kualitas pendidikan kedokteran, memperkuat penelitian biomedis, meningkatkan jumlah publikasi ilmiah, memperkuat kualitas pelayanan kesehatan, dan memperkuat harmoniasi kerjasama antara profesi kesehatan. Saat ini ada tuntutan akan restrukturisasi edukasi praktisi kesehatan untuk benar-benar memenuhi kebutuhan masyarakat. Penelitian dan inovasi menjadi salah satu jembatan untuk memenuhi harapan tersebut. Dalam sistem AHS maka RS jejaring akan diberdayakan kemampuannya untuk melakukan penelitian translasional, yaitu from the bench to the bed side and community (dari laboratorium diaplikasikan ke pasien serta masyarakat) dan sebaliknya.1,2

Fakultas kedokteran dan RS serta jejaring lain perlu membantuk suatu struktur organisasi yang memastikan Academic Health System ini berjalan baik. Tantangan terbesardari aplikasi pendekatan ini adalah menyusun strategi dan membangun budaya yang baik untuk sistem yang baru ini. Tahap awal yang mendasari keberhasilan system AHS adalah menyatukan ego masing-masing pihak dengan struktur terpisah, namun memiliki tujuan yang sama (common goals) untuk mengintegrasikan proses pendidikan, pelayanan, dan penelitian. Dua atau lebih institusi yang memiliki struktur yang terpisah harus memiliki semangat yang sama untuk menjadikan pendidikan, penelitian, dan pelayanan menjadi satu kesatuan terintegrasi. Sinergi FK dan RS dan institusi pelayanan kesehatan lainnya harus dikembangkan, karena health bukan saja bersifat kuratif di RS, namun juga promotif dan preventif. ${ }^{3}$ 


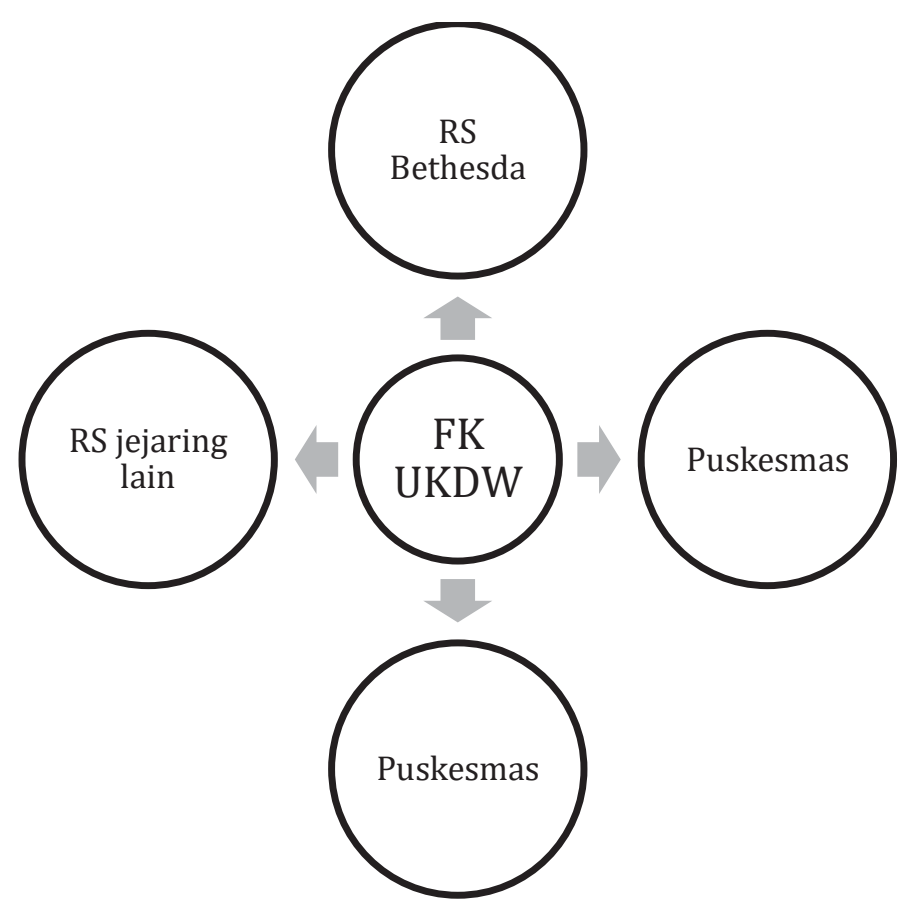

Gambar 2. Integrasi Academic Health System

Berbeda dengan disiplin ilmu yang lain, finishing touch dan kawah candradimuka pendidikan dokter adalah RS dan Puskemas sebagai medan belajar aplikatif sebelum diterjunkan sebagai tenaga medis mandiri. Pelayanan dan pembelajaran harus terintegrasi dengan baik dan diperlukan kelembagaan yang jelas untuk mengintegrasikan hal tersebut dan mengawal tujuan yang terukur. Untuk mendukung keberhasilan integrated team work tersebut diperlukan nahkoda yang berperan sebagai transformational leader. Pusat dan kelembagaan yang mengawal Academic Health System seharusnya berada di Fakultas Kedokteran sebagai intitusi akademik yang netral dan bertujuan utama ilmiah. Langkah awal adalah merubah kultur dan karakter orang-orang yang terlibat (dosen di FK, dosen pembimbing klinik, stakeholders lain di dinas kesehatan dan puskesmas) untuk mau mengintegrasi pendidikan dan pelayanan kesehatan. Bukti empirik menunjukkan bahwa membangun kultur tidak mudah, sehingga perlu internalisasi dan agen-agen perubah.1,3 Kelembagaan tersebut pada umumnya bekerja dengan urut-urutan sebagai berikut: 1) Membangun komitmen stakeholders, lalu membuat rencana strategis bersama dengan para stakeholders, 2) Membuat panduan, menetapkan tujuan yang terukur, dan struktur yang jelas dalam implementasinya, 3) Implementasi program bersama, evaluasi, dan monitoring berkala. 4) Aplikasi hasil penelitian dan inovasi dalam bentuk peningkatan pelayanan, diseminasi hasil penelitian kepada masyarakat umum maupun sains lewat publikasi dan penyuluhan.

Pelaksanaan pendekatan integrasi antara pendidikan, penelitian, dan pelayanan kesehatan melalui AHS ini adalah sebagian jawaban dari perubahan situasi global dan nasional saat ini. Tugas lulusan FK yang semakin kompleks harus dipersiapkan dengan matang selama proses pendidikan. Dalam sistem JKN ini dokter lulusan FK UKDW akan menjadi dokter layanan primer yang berfungsi sebagai gatekeeper dan harus mampu bekerja sama dengan profesi lain dalam patient centered care. Tuntutan kemajuan ilmu dan teknologi yang aplikatif di bidang klinis dan kesehatan masyarakat juga menjadikan dorongan dan peluang 
yang baik bagi semua pihak untuk bekerjasama. Integrasi pendidikan dan pelayanan kesehatan serta penelitian dalam AHS akan mampu membantu menyiapkan dokter lulusan FK UKDW yang mumpuni dalam memberikan pelayanan kesehatan.

\section{DAFTAR PUSTAKA}

1. Washington AE, Coye MJ, Feinberg DT. Academic Health Centers and the Evolution of Health Care System. JAMA 2013 Nov 13; 310(18): 1929-1930

2. Borden WB, Mushlin AI, Gordon JE et al. A New Conceptual Framework for Academic Health System. Acad. Medicine 2015May; 90(5): 00-00

3. Barrett DJ. The Evolving Organizational Structure of Academic Health Center: The Case of University of Florida. Acad. Medicine 2008 Sept; 83(9): 804-808 